This item was submitted to Loughborough's Institutional Repository (https://dspace.lboro.ac.uk/) by the author and is made available under the following Creative Commons Licence conditions.

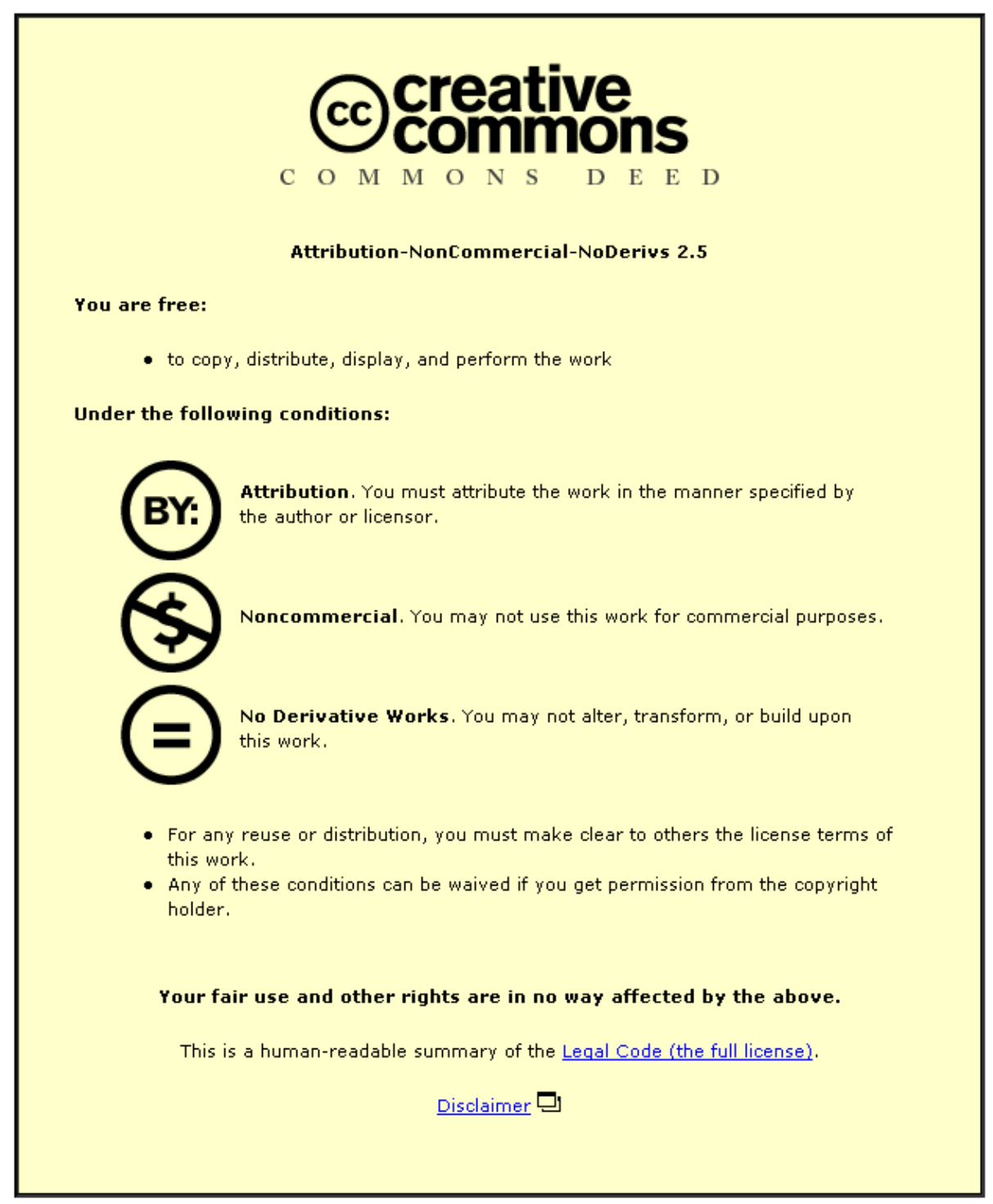

For the full text of this licence, please go to: http://creativecommons.org/licenses/by-nc-nd/2.5/ 


\title{
THE INFLUENCE OF POLARITY ON FLUX AND REJECTION BEHAVIOUR IN SOLVENT RESISTANT NANOFILTRATION - EXPERIMENTAL OBSERVATIONS
}

\author{
E.S. Tarleton ${ }^{1}$ (e.s.tarleton@lboro.ac.uk), J.P. Robinson ${ }^{2}$, C.R. Millington ${ }^{3}$, A. Nijmeijer ${ }^{4}$ and M.L.
} Taylor $^{5}$

${ }^{1}$ Advanced Separation Technologies Group, Department of Chemical Engineering, Loughborough University, Loughborough, Leicestershire LE11 3TU, UK.

${ }^{2}$ now at School of Chemical, Environmental and Mining Engineering, The University of Nottingham NG7 2RD, UK.

${ }^{3}$ Shell Global Solutions, Cheshire Innovation Park, P.O. Box 1, Chester CH1 3SH, UK.

${ }^{4}$ Shell Global Solutions International BV, P.O. Box 38000, 1030 BN Amsterdam, The Netherlands.

${ }^{5}$ Department of Chemical Engineering, University of Sheffield, Sheffield, South Yorkshire S1 3JD, UK.

\begin{abstract}
The separation characteristics of a dense polydimethylsiloxane (PDMS) membrane were studied using mixtures comprising xylene, cyclohexane or n-heptane with oxygenate components at concentrations up to $75 \%$. The effects of polarity on flux and rejection performance were determined through a test matrix of solvent type, concentration, filtration pressure, crossflow rate and the degree of membrane crosslinking.
\end{abstract}

In all cases involving alcohols, the more polar compound in the feed mixture was partially rejected by the membrane and the extent of rejection was dependent on the polarity as quantified by solubility parameter. The rejection-concentration profiles for several alcohol/solvent mixtures exhibited a maximum, with the highest rejection around 30\%. Mixtures containing MTBE did not separate, i.e. no rejection was observed.

Rejection increased with increasing pressure and crossflow rate but was largely unaffected by the degree of membrane crosslinking. Component flux was affected by the oxygenate concentration in the mixture, which was attributed in part to changes in the degree of membrane swelling with composition. Experimental findings suggest that the separation is primarily governed by multicomponent solvent/oxygenate/membrane swelling equilibria, and results compare favourably with swelling isotherms available in the open literature.

\section{KEYWORDS}

Nanofiltration; SRNF; Membrane; PDMS; Non-aqueous; Organic solvents; Osmotic pressure; Rejection; Swelling; Solution-diffusion

\section{INTRODUCTION}

The growing interest in solvent resistant nanofiltration (SRNF) is evidenced by the recent increase in the number of published papers and the realisation that a new generation of polymeric membranes are sufficiently robust to withstand more aggressive process environments. Although the literature is by no means extensive, a number of researchers have investigated the nanofiltration of organic feeds containing alcohol. The majority have determined flux and/or rejection performance at the laboratory scale with relatively simple deadend permeation or stirred cell apparati in order to establish fundamental data, membrane stability and/or an insight into transport mechanisms [1-19]. Much of the work has focussed on the behaviour of pure components and whilst some workers have identified membrane swelling as an important 
parameter, there is much discrepancy in the literature regarding flux/rejection behaviour and the underlying reasons for observations.

Recent work by the authors in SRNF examined the flux behaviour of low polarity alkyl and aromatic solvents with radiation crosslinked polydimethylsiloxane (PDMS) membranes. Results indicated that solvent flux was predominantly governed by viscosity and the degree of membrane swelling, with the latter characterised by the solubility parameter $(\delta)[20]$ where $\delta=\sqrt{\delta_{p}^{2}+\delta_{d}^{2}+\delta_{h}^{2}} ; \delta_{p}$, $\delta_{d}$ and $\delta_{h}$ are components respectively accounting for polarity, dispersion and hydrogen bonding. One of the principal findings was that low polarity solvents and solutes which are less than $1 \mathrm{~nm}$ in size do not separate from their parent solvents [21-23]. The aim of the current paper is to extend the authors previous work and report experimental data for a range of solvent/oxygenate mixtures. The addition of oxygenate components raises the influence of polarity to an extent characterised by the potential enhancement of $\delta_{p}$ and $\delta_{h}$, and hence $\delta$. Results are compared in terms of the overall solubility parameter as this allows differentiation between the non-polar solvents used.

\section{EXPERIMENTAL}

\section{Membranes}

All experiments used polyacrylonitrile (PAN)/polydimethylsiloxane (PDMS) composite membranes supplied by GKSS Forschungszentrum. The PAN substrate has previously been shown to be inactive [20] whilst the radiation crosslinked, hydrophobic and selective PDMS layer exhibited a nominal thickness of $2 \mu \mathrm{m}$ in its virgin state. The membranes exhibited a range of crosslinking densities as characterised by the irradiation dose (higher dose corresponds to more crosslinking) and solvent permeability (low permeability corresponds to more crosslinking) as shown in Table 1. No appreciable deterioration in membrane performance, in terms of flux or rejection, was observed over the duration of the study. New membranes were mounted dry in the filtration cell, and remained in place until all necessary experiments were completed. Conditioning of the membrane was performed between different solvent mixtures to remove traces of the previous test-mixture, some details are provided in a previous work [22].

\section{Materials}

Table 2 details the physical properties of the solvents used in this study. All components were supplied by Sigma-Aldrich and had initial purities in excess of $99 \%$. Concentrations of the binary mixtures were determined using a refractive index technique.

\section{Apparatus}

The solvent/oxygenate systems were studied in the crossflow membrane filtration apparatus shown schematically in Figure 1. The solvent/alcohol mixture was added to the reservoir $(A)$ from which an air-driven pump (B) delivered the fluid to the membrane module $(C)$ via a flow meter $(F)$, a flow control valve (V6) and a $15 \mu \mathrm{m}$ rated pre-filter (D). Permeate could either be circulated back to the reservoir or collected separately for subsequent sample analysis. The retentate stream returned to the reservoir through a cooler $(E)$ that employed the exhaust air stream from the pump to maintain the temperature of the circulating fluid. Trans-membrane pressure and crossflow rate were controlled primarily by the back-pressure regulator (V7) and the air-regulator to the pump (V2). The circular, flat sheet membrane was mounted in an Osmonics DESAL membrane cell to give a wetted surface area of $75 \mathrm{~cm}^{2}$.

The maximum filtration pressure and crossflow rate obtainable were 9 bar and $1.01 \mathrm{~min}^{-1}$ respectively. As feed mixture viscosity approached $1 \mathrm{mPa}$, so the available operating envelope was reduced. 


\section{Procedure}

All the reported data were obtained using one litre of feed in the reservoir and a $10 \%$ stage cut. Prior to an experiment the test solution was circulated at very low pressure for several minutes with no permeation to remove any trapped air in the system. With the pressure and crossflow set to the desired values, permeate was circulated back to the reservoir for a fixed period in order to establish equilibrium conditions. Permeate was subsequently diverted and collected in a separate vessel and this sample was used to determine flux and concentration. Evaporation from the permeate collection vessel was negligible, and all results were found to satisfy a mass balance to within $1 \%$. Several of the datasets reported in this paper were duplicated, and it was found that the rejection measurements for ethanol, $n$ - and i-propanol could be repeated to within $\pm 1 \%$. Methanol rejection data were repeatable to $\pm 0.3 \%$, the difference in repeatability being primarily due to the resolution of concentration measurements using the refractive index technique.

\section{RESULTS AND DISCUSSION}

The effects of polarity on flux and rejection performance were principally examined through a test matrix of mixture type, oxygenate concentration, filtration pressure, crossflow rate and the degree of crosslinking of the membrane material; $\delta$ was used to characterise the degree of polarity. For mixtures containing propanol, only limited data could be acquired due to viscosity-induced apparatus restrictions. The authors have previously reported how mixtures of low polarity solvents, such as n-heptane/xylene and n-hexane/cyclohexane, exhibited no separation when permeating through membranes identical to those used in the current study [20]. The fluxes of pure methanol and ethanol were also very low (estimated to be at least two orders of magnitude less than, for instance, xylene or heptane) and sufficient to preclude accurate determination with the apparatus in Figure 1.

\section{Effects of Crossflow Rate}

Figure 2 shows the effects of crossflow rate on the rejection of ethanol at 5 bar from a xylene/ethanol solution. Of note is that the rejection increases with crossflow rate, a phenomena also observed by other workers both in the SRNF [24] and aqueous NF/RO fields [25, 26]. Since rejection of the oxygenate occurs, its concentration at the feed-side of the membrane is higher than that in the bulk feed liquid, which can give rise to concentration polarisation effects. The transport of the oxygenate across the membrane may thus be artificially enhanced due to the raised concentration at the membrane surface, which in turn tends to reduce the observed rejection. Polarisation can be minimised by applying a shear-force to the membrane surface which enhances the diffusion of the oxygenate from the membrane surface back to the bulk feed, and in this particular example the shear force is varied by changing the hydrodynamic conditions above the surface of the membrane. Higher crossflow rates promote a greater shear force which leads to improved oxygenate rejections. Over the range of crossflow investigated no plateau in rejection was recorded, a result that differs from that previously observed by the authors for the rejection of a low-polarity solute from a binary mixture [22].

The presence of the effects noted above has several implications for the comparison of flux and separation characteristics of the range of solvent/oxygenate mixtures. The density and viscosity of each mixture will induce unique hydrodynamic conditions for a fixed crossflow rate, hence a comparison of each mixture at a single flow rate is potentially misleading. Instead, different mixtures are compared at specific hydrodynamic conditions corresponding to Reynolds number. The design of the DESAL membrane cell is such that the effective diameter of the flowing fluid element is difficult to reliably estimate. However, the cell dimensions are the same regardless of the mixture studied, hence an equivalent Reynolds number can be used which is based on the crossflow rate and the density and viscosity of the test mixture, i.e. $Q \rho / \mu$. Experiments to assess 
the effects of alcohol type and concentration, solvent-type and pressure were performed at crossflow rates corresponding to $Q \rho / \mu=8 \mathrm{~m}$, a condition chosen to allow optimal experimental flexibility given the limitations of the apparatus with high viscosity feed streams.

It is noted that although concentration-polarisation is usually associated with changes in solvent flux, such effects cannot be delineated in this instance due to the added effect of membrane swelling as induced by the binary components in the feed. Swelling is discussed in greater detail in subsequent sections.

\section{Effects of Oxygenate Type and Concentration}

Figure 3 shows the rejection-concentration profiles for xylene/oxygenate mixtures at a pressure of 5 bar. The highest alcohol rejections were recorded for methanol, which exhibits the highest polarity as characterised by its solubility parameter $\left(\delta=29.2 \mathrm{MPa}^{0.5}\right)^{* \star}$. The data for the other tested alcohols show successively lower rejections dependent on the polarity of the alcohol component, i.e. the lowest rejections were recorded for i-propanol $\left(\delta=23.6 \mathrm{MPa}^{0.5}\right)$. The least polar of all the oxygenates, MTBE, did not separate from xylene under any of the experimental conditions studied. This is in agreement with previous findings where solvent mixtures such as heptane/xylene and hexane/cyclohexane with $\delta$ in the range $15 \rightarrow 19 \mathrm{MPa}^{0.5}$ showed no separation when permeated through identical membranes [20]. Of note is that the trend shown in Figure 3 is the opposite of what would be expected if the rejection were governed by the size of the alcohol. Indeed, the smallest of the alcohols, methanol, is smaller than the solvent with which it is mixed (see Table 2) which indicates that the primary rejection mechanism is governed by polarity rather than size.

From Figure 3, the rejection-concentration profiles for methanol and ethanol clearly exhibit maxima, which the authors believe to be a unique finding for SRNF membranes. In an attempt to account for the non-ideality of the mixtures used in this work, Figure 4 details the rejection of methanol and ethanol relative to their activities in the mixture (calculated using the Wilson equation from activity coefficients at infinite dilution [27-29]). Figure 4 indicates that peak alcohol rejections are still evident when activities are taken into consideration which in turn implies that rejection behaviour is likely to be influenced by phenomenon other than the non-ideality of the solvent/alcohol binary mixtures.

The oxygenate compounds were studied at sufficient concentrations for their fluxes to be appreciable relative to that of the other solvent present, in which case the results can be expressed in terms of solvent and oxygenate flux as well as oxygenate rejection. Although dependent on alcohol concentration, in general when an alcohol was in used in combination with another solvent the alcohol flux was significantly higher than for permeation of the pure alcohol through a particular membrane. Figure 5 shows the typical effects of component activity on flux, in this particular case for ethanol/xylene mixtures. The solvent flux increases with increasing solvent activity, whereas the alcohol flux appears to exhibit a peak. Similar behaviour was observed for each set of solvent/alcohol mixtures studied. An increase in concentration of either species in the feed could perhaps be expected to cause a proportional increase in a component flux, however this was not the case as depicted in Figure 6 . With the component flux rationalised to account for its concentration in the feed $\left(J_{i} / V_{i}\right)$, it can be seen that ethanol and methanol fluxes decline as more alcohol is added to the feed mixture.

The data in Figure 6 are likely to be influenced by at least two contributory factors:

\footnotetext{
${ }^{* *}$ The rejections with all the tested alcohols were relatively low and below those potentially acceptable in nanofiltration. However, the nature of possible applications means that understanding rejection behaviour when alcohols are present is of primary importance and low rejections do not necessarily imply restrictions on the technology. 
- Changes in the degree of membrane swelling, which affects mixture permeability [20,30].

- Changes in the viscosity of the mixture with concentration; even in dense membranes viscosity has been shown to influence solvent permeation [4, 20, 31].

Addition of methanol to xylene will yield a slight decrease in the mixture viscosity, conversely ethanol causes the mixture viscosity to increase (based on pure component viscosities, see Table 2 ). Decreasing the mixture viscosity would be expected to increase the component flux, however this is not the case highlighted in Figure 6. It is apparent, therefore, that the degree of swelling has a significantly more pronounced effect on component flux than the viscosity of the mixture.

For pure solvents, some of the authors have previously shown a relationship between the solubility parameter of the feed stream $\left(\delta_{F}\right)$ and the corresponding value for a PDMS nanofiltration membrane $\left(\delta_{P D M S}=15.5 \mathrm{MPa}^{0.5}\right)$; when $\delta_{F}$ is closer to $\delta_{P D M S}$ there is increased membrane swelling and a higher solvent permeability [20,21]. Addition of the more-polar alcohol components to xylene increases $\delta_{\text {mix }}$ which could be expected to reduce the overall degree of membrane swelling, although analysis beyond the qualitative is difficult since such mixtures cannot be treated as ideal [32]. Measurements of the degree of swelling of the PDMS layer on a membrane have been performed for several solvent/oxygenate mixtures [33]. Figure 7 represents a typical example and is taken directly from the cited literature. The degree of swelling clearly reduces with increasing alcohol concentration, and although some data scatter is evident, it may be inferred that a qualitative relationship exists between the swelling ratio $\left(V_{\text {swollen }} / V_{d r y}\right)$ and the polarity of the alcohol. Of note is that with the equipment currently available to the authors no data could be obtained in relation to multi-component swelling equilibria, i.e. the preferential sorption of one or other of the mixture components. Due to the thin nature of the irradiated PDMS layer on the membranes only the overall degree of swelling induced by the mixture could be detected. The order in which the data appear in Figure 7 is interesting and in-line with the alcohol rejection data shown in Figure 2 whereby the extent to which the alcohol/solvent mixture swells the membrane correlates with the degree to which the alcohol component is rejected.

\section{Effects of Filtration Pressure}

Methanol and ethanol rejection increased with filtration pressure for all tested alcohol concentrations and Figure 8 shows representative data for xylene/ethanol mixtures. Whilst the authors believe this to be a unique finding for alcohols mixed with other solvents, several independent researchers have previously reported increased rejection with pressure for solvent/solute combinations [8, 34, 35]. It is noted that the order in which the data appear in Figure 8 is non-sequential in terms of ethanol concentration although entirely consistent with the bellshaped curves in Figure 3.

Figure 9 portrays the effects of filtration pressure on the total flux. It is clear that linear regressions for each data sequence provide positive intercepts on the $x$-axis, and a previous report states that these can be related to osmotic pressure [8]. For ideal mixtures the osmotic pressure can be estimated using the Van't Hoff equation:

$$
\Delta \pi=\frac{R_{G} T \Delta C_{i}}{v_{i}}
$$

Equation (1) is valid when the membrane is impermeable to one of the two species in the mixture. Since both the solvent and alcohol permeate the membrane to an appreciable extent, and given the non-ideality of these mixtures, the validity of the Van't Hoff equation in this instance is questionable. A potential alternative approach is to approximate the osmotic pressure using an adapted form of the solution-diffusion (SD) model. According to the SD approach there is no pressure gradient across the depth of the membrane selective layer, the pressure is constant 
throughout the membrane depth and at the same pressure as the feed-liquid, with an instantaneous drop in pressure between the permeate-side of the membrane and the permeate liquid [36]. The activity of a component, $i$, at the permeate side of the membrane can be related to its activity in the permeate liquid:

$$
a_{i P}^{m}=a_{i P} \exp \left(\frac{-v_{i} \Delta P}{R_{G} T}\right)
$$

At the feed side of the membrane there is no pressure difference, hence the activity of species $i$ on the feed-side of the membrane is equal to its activity in the feed liquid:

$$
a_{i F}^{m}=a_{i F}
$$

The driving force for transport across the membrane according to SD is an activity gradient, so at osmotic equilibrium the activity gradient is zero and hence:

$$
a_{i F}^{m}=a_{i P}^{m} \quad \rightarrow \quad \frac{a_{i F}}{a_{i P}}=\exp \left(\frac{-v_{i} \Delta \pi}{R_{G} T}\right)
$$

The osmotic pressure can therefore be expressed in terms of the difference in activity of species $i$ :

$$
\Delta \pi=\frac{R_{G} T}{v_{i}} \ln \left(\frac{a_{i P}}{a_{i F}}\right)
$$

Specific to the mixtures used in this work, the activity of the solvent is higher in the permeate than in the feed due to removal of the alcohol, therefore a pressure is required that is above the osmotic pressure in order to allow the solvent to permeate. The theoretical osmotic pressures have been estimated for the xylene/ethanol mixtures using both the Van't Hoff (Equation (1)) and solutiondiffusion (Equation (5)) approaches as shown in Table 3. Since the ethanol rejection varies with pressure, the permeate activities and concentrations have been arbitrarily chosen at 5 bar.

It is apparent from Table 3 that the osmotic pressures from the Van't Hoff equation are above the pressure at which the experiments were performed. In contrast, the osmotic pressures predicted by the SD equation appear to be more realistic, particularly at low ethanol concentrations. However, at higher concentrations the model predicts osmotic pressures that are higher than the 5 bar at which the experimental data were obtained. The Van't Hoff equation in particular appears to be limited in this case due to the appreciable ethanol flux through the membrane, a case which is far removed from the ideal scenario where only one species in a binary mixture is able to permeate the membrane. The validity of the SD approach may also be limited in the same way, indeed the result of Equation (5) assumes that solvent permeation is predominant. It is clear that the traditional methods for estimating osmotic pressure as quoted in Equations (1) and (5) cannot be used in the case of the solvent/alcohol mixtures used in this study, and that the transport of both species must be fully considered if the osmotic pressures are to be rationalised. Such a transport analysis is beyond the scope of this paper.

\section{Effects of Solvent Type}

The effects of solvent type on ethanol rejection are shown in Figure 10 for three different solvent/ethanol mixtures. Previous reports in the SRNF literature state that solute rejection is dependent on solvent-type [6, 9, 21, 22, 34], and it appears that the data shown in Figure 10 are consistent with these findings. Whilst mechanisms for rejection in different solvents have been proposed for separations based on the size of the solute [22, 23], the data in Figure 10 cannot be 
rationalised using such methods as the separation mechanism appears to be a result of component polarity rather than size. It is postulated (and discussed below) that the separation of the more polar component in the mixture is influenced to a large degree by multicomponent swelling equilibria, where the difference in activity between different solvent/alcohol/membrane systems accounts for the observed rejection in different solvents.

\section{Effect of Membrane Crosslinking}

The effects of crosslinking were evaluated by studying the behaviour of solvent/alcohol mixtures with membranes of different irradiation doses, 50 and $200 \mathrm{kGy}$, where the latter is more crosslinked as confirmed by measurements of reduced swelling for a range of solvents. In the context of the membranes tested in this paper, PDMS which is more crosslinked swells to a lesser extent to yield a lower solvent permeability; such a result is shown in Table 1 where the highest xylene permeability occurs with the least crosslinked membrane. Data were obtained for all of the solvent/alcohol mixtures previously described, and representative data for ethanol/xylene mixtures are shown in Figures 11 and 12. The rejection of ethanol appears to be largely independent of the degree of crosslinking of the PDMS material, that is to say the overall degree of membrane swelling has little impact on alcohol rejection. Interestingly, the component fluxes were significantly different with each membrane sample, and ethanol fluxes are shown in Figure 12 as an example. Similar behaviour occurred with membrane samples $1 \& 2$; despite the different permeability the ethanol rejections with each sample could be plotted together such that the two datasets overlayed each other (Figure 3, for instance, shows data plotted in this manner).

The ethanol rejection can be derived from the individual solvent and ethanol fluxes, so it is somewhat surprising that the rejection remains largely unchanged despite the differences in component fluxes. This in turn implies that the overall degree of swelling affects both alcohol and solvent transport to the same degree, and hence by definition the ratio of ethanol to solvent flux is the same in each case. Such results could be seen as evidence that there is little degree of separation during permeation through the depth of the membrane (i.e. coupled flows), and that the majority of the rejection occurs upon sorption into the PDMS layer.

\section{Overall Implications}

It is unlikely that rejection by a size exclusion mechanism is prevalent for alcohols given that their molecular size is equivalent to, if not smaller than the solvents with which they are mixed. Indeed, the characteristics of alcohol flux and rejection relative to pressure and concentration are quite different to those obtained when size-exclusion is predominant $[9,22,37]$. It is more probable that the high polarity of the alcohol in conjunction with the hydrophobicity of the membrane plays a dominant role which is emphasised by the non-separation of MTBE, a low-polarity compound that is structurally and chemically different from the xylene solvent. Consideration of component polarity is one method by which interactions with the membrane material can be rationalised, and in the case of a hydrophobic membrane such as PDMS a substance with a high polarity (e.g. methanol) is likely to penetrate into the membrane to a lesser extent than one which is more hydrophobic (e.g. xylene). A more comprehensive measure of such interactions may be obtained with multicomponent swelling equilibria, which considers the polarity (in the form of an interaction parameter, $X$ ) and activity of each component in a mixture.

Whilst exact mechanisms can only be speculative at this stage, much of the experimental data suggest that alcohol rejection is primarily due to preferential sorption of the solvent, and that this may then lead to several other phenomena. Although no partition measurements were obtained, Favre et al. [38] studied swelling equilibria for ethanol/toluene/PDMS systems, amongst others. Using their experimental data as a basis, the rejection due to swelling equilibria was determined via the concentrations of ethanol relative to the total liquid volume within the swollen polymer, and the results are shown in Figure 13. 
It is clear that the bell-shaped swelling isotherm in Figure 13 is of a similar shape to the rejection profiles of methanol and ethanol in Figures 2 and 3 . Although toluene was studied by Favre et al. [38] and xylene was used in this study, the two solvents are chemically similar, and hence the data shown in Figure 13 are likely to provide a qualitative indication of the behaviour that would be expected with xylene. The equilibrium data provides further evidence (along with the effect of crosslinking) that the predominant factor governing the rejection of polar compounds is that which occurs at the membrane surface.

Although interpretation of possible transport mechanisms has largely been omitted from this paper, a considerable amount of consistent and repeatable data have been obtained in support of those shown. The data give insights into the effects of polarity on the flux and separation performance of hydrophobic SRNF membranes which have not been reported by other workers in the field. It is intended that a future paper will provide a quantitative assessment of the data shown here using, for instance, the Flory-Huggins ternary equations, the solution-diffusion model and several mechanistic techniques.

\section{CONCLUSIONS}

This study gives an insight into the flux and rejection behaviour of mixtures of non-polar/polar solvents under a range of operating conditions with dense PDMS nanofiltration membranes. Preferential transport of the non-polar solvent occurred in each case, and the degree of rejection was dependent on the polarity of the oxygenate as quantified by its solubility parameter, $\delta$. Mixtures with $15<\delta<19 \mathrm{MPa}^{0.5}$ did not separate, higher rejections were obtained with the oxygenate components that exhibited higher values of $\delta$. The flux of each component in the mixture was affected by pressure, mixture composition and the degree of membrane swelling. Rejection was also affected by pressure and mixture composition but was found to be largely independent of the degree of membrane swelling. The latter suggests that rejection is primarily affected by multicomponent swelling equilibria upon sorption into the selective layer. Whilst consistent and repeatable data has been obtained for a range of mixtures and operating conditions, the transport mechanisms for polar/non-polar mixtures are difficult to infer. The results are in qualitative agreement with component polarity and experimental sorption isotherms, however, a quantitative assessment of potential mechanisms is yet to be determined.

\section{ACKNOWLEDGEMENTS}

The authors would like to thank Shell Global Solutions (UK) for supplying the project funding, technical hardware and some materials. EPSRC are also acknowledged for part-funding the project. The PDMS membranes used in the study were kindly supplied by GKSS Forschungszentrum.

\section{NOMENCLATURE}

$\begin{array}{ll}a & \text { Component activity } \\ \Delta C & \text { Molar concentration difference } \\ J & \text { Flux }\left(1 / \mathrm{m}^{2} \mathrm{~h}\right) \\ \Delta P & \text { Filtration pressure (bar) } \\ Q & \text { Crossflow rate }(\mathrm{l} / \mathrm{min}) \\ R_{G} & 0.08314\left(\text { bar } \mathrm{m}^{3} / \mathrm{kmol} \mathrm{K}\right) \\ T & \text { Temperature }(\mathrm{K}) \\ V & \text { Volume fraction }\end{array}$




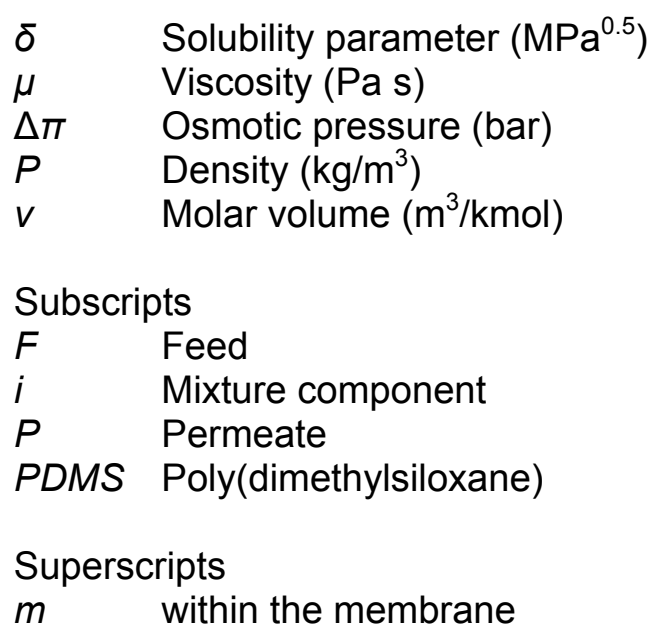

\section{REFERENCES}

1. S.J. Han, S.S. Luthra, L.G. Peeva, X.J. Yang and A.G. Livingston. Insights into the transport of toluene and phenol through organic solvent nanofiltration membranes. Sep. Sci. Technol. 38(9) (2003) 1899-1923.

2. D.R. Machado, D. Hasson and R. Semiat. Effect of solvent properties on permeate flow through nanofiltration membranes: Part I: Investigation of parameters affecting solvent flux. J. Membrane Sci. 163(1) (1999) 93-102.

3. X.J. Yang, A.G. Livingston and L. Freitas dos Santos. Experimental observations of nanofiltration with organic solvents. J. Membrane Sci. 190 (2001) 45-55.

4. I.F.J. Vankelecom, K. De Smet, L.E.M. Gevers, A. Livingston, D. Nair, S. Aerts, S. Kuypers and P.A. Jacobs. Physico-chemical interpretation of the SRNF transport mechanism for solvents through dense silicone membrane. J. Membrane Sci. 231 (2004) 99-108.

5. B. van der Bruggen, J. Geens and C. Vandecasteele. Fluxes and rejections for nanofiltration with solvent stable polymeric membranes in water, ethanol and n-hexane. Chem. Eng. Sci. 57 (2002) 2511-2518.

6. B. van der Bruggen, J. Geens and C. Vandecasteele. Influence of organic solvents on the performance of polymeric nanofiltration membranes. Sep. Sci. Technol. 37(4) (2002) 783-797.

7. D. Bhanushali, S. Kloos, C. Kurth and D. Bhattacharyya. Performance of solvent-resistant membranes for non-aqueous systems: Solvent permeation results and modelling. J. Membrane Sci. 189(1) (2001) 1-21.

8. N. Stafie, D.F. Stamatialis and M. Wessling. Insight into the transport of hexane-solute systems through tailor-made composite membranes. J. Membrane Sci. 228 (2003) 103-116.

9. D. Bhanushali, S. Kloos and D. Bhattacharyya. Solute transport in solvent-resistant nanofiltration membranes for non-aqueous systems: Experimental results and the role of solute-solvent coupling. J. Membrane Sci. 208(1-2) (2002) 343-359.

10. T. Tsuru, T. Suduo, S. Kawahara, T. Yoshioka and M. Asaeda. Permeation of liquids through inorganic nanofiltration membranes. J. Colloid Interface Sci. 228(2) (2000) 292-296. 
11. C. Guizard, A. Ayral and A. Julbe. Potentiality of organic solvents filtration with ceramic membranes. A comparison with polymer membranes. Desalination 147(1-3) (2002) 275-280.

12. R. Shukla and M. Cheryan. Stability and performance of ultrafiltration membranes in aqueous ethanol. Sep. Sci. Technol. 38(7) (2003) 1533-1547.

13. T. Tsuru, M. Miyawaki, H. Kondo, T. Yoshioka and M. Asaeda. Inorganic porous membranes for nanofiltration of non-aqueous solutions. Sep. Purif. Technol. 32(7) (2003) 105-109.

14. T. Tsuru, T. Sudoh, T. Yoshioka and M. Asaeda. Nanofiltration in non-aqueous solutions by porous silica-zirconia membranes. J. Membrane Sci. 185(2) (2001) 253-261.

15. R. Shukla and M. Cheryan. Performance of ultrafiltration membranes in ethanol-water solutions: Effect of membrane conditioning. J. Membrane Sci. 198(1) (2002) 75-85.

16. J. Geens, B. van der Bruggen and C. Vandecasteele. Characterisation of the solvent stability of polymeric nanofiltration membranes by measurement of contact angles and swelling. Chem. Eng. Sci., 59 (2004) 1161-1164.

17. B. van der Bruggen, J. Schaep, D. Wilms and C. Vandecasteele. A comparison of models to describe the maximal retention of organic molecules in nanofiltration. Sep. Sci. Technol. 35(4) (2000) 169-182.

18. Q.T. Nguyen, E. Favre, Z.H. Ping and J. Néel. Clustering of solvents in membranes and its influence on membrane transport properties. J. Membrane Sci. 113 (1996) 137-150.

19. S-S. Chen, J.S. Taylor, L.A. Mulford and C.D. Norris. Influences of molecular weight, molecular size, flux and recovery of aromatic pesticides by nanofiltration membranes. Desalination 160 (2004) 103-111.

20. J.P. Robinson, E.S. Tarleton, C.R. Millington and A. Nijmeijer. Solvent flux through dense polymeric nanofiltration membranes. J. Membrane Sci. 230 (2004) 29-37.

21. J.P. Robinson, E.S. Tarleton, C.R. Millington and A. Nijmeijer. Evidence for swelling-induced pore structure in dense PDMS nanofiltration membranes. FILTRATION 4(1) (2004) 50-56.

22. E.S. Tarleton, J.P. Robinson, C.R. Millington and A. Nijmeijer. Non-aqueous nanofiltration: Solute rejection in low-polarity binary systems. J. Membrane Sci. 252 (2005) 123-131.

23. J.P. Robinson, E.S. Tarleton, C.R. Millington, A. Nijmeijer and K. Ebert. Influence of crosslinking and process parameters on the separation performance of poly(dimethylsiloxane) nanofiltration membranes. Ind. Eng. Chem. Res. 44 (2005) 3238-3248.

24. L.G. Peeva, E. Gibbins, S.S. Luthra, L.S. White, R.P. Stateva and A.G. Livingston. Effect of concentration polarisation and osmotic pressure on flux in organic solvent nanofiltration. $J$. Membrane Sci. 236 (2004) 121-136.

25. A.W. Mohammad and M.S. Takriff. Predicting flux and rejection of multicomponent salts mixture in nanofiltration membranes. Desalination 157 (2003) 105-111.

26. M.P.S. Ramani. Mass transport mechanism on the high-pressure side in reverse osmosis: an analysis. Chem. Eng. Sci. 47 (1992) 4099-4105.

27. J. Gmehling and U. Onken. Vapour-liquid equilibrium data collection. Organic hydroxy compounds: Alcohols. DECHEMA Chemical Data Series 1(2a), Frankfurt/Main 1977. 
28. J. Gmehling, U. Onken and W. Arlt. Vapour-liquid equilibrium data collection. Organic hydroxy compounds: Alcohols supplement 1. DECHEMA Chemical Data Series 1(2c), Frankfurt/Main 1982.

29. J. Gmehling, U. Onken and J.R. Rarey-Nies. Vapour-liquid equilibrium data collection. Organic hydroxy compounds: Alcohols supplement 3. DECHEMA Chemical Data Series, 1(2e), Frankfurt/Main 1988.

30. D.R. Paul, J.D. Paciotti and O.M. Ebra-Lima. Hydraulic permeation of liquids through swollen polymeric networks. J. Applied Polymer Sci. 19 (1975) 1837-1845.

31. L.S. White. Transport properties of a polyimide solvent resistant nanofiltration membrane. J. Membrane Sci. 205 (2002) 191-202.

32. A.F.M. Barton. CRC Handbook of solubility parameters and other cohesion parameters. CRC Press, London, 1983.

33. E.S. Tarleton, J.P. Robinson, S.J. Smith and J.J.W. Na. A new experimental method for measuring solvent induced swelling in nanofiltration membranes. J. Membrane Sci. 261 (2005) 129-135.

34. J.T. Scarpello, D. Nair, L.M. Freitas dos Santos, L.S. White and A.G. Livingston. The separation of homogeneous organometallic catalysts using solvent resistant nanofiltration. J. Membrane Sci. 203 (2002) 71-85.

35. J.A. Whu, B.C. Baltzis and K.K. Sirkar. Nanofiltration studies of larger organic microsolutes in methanol solutions. J. Membrane Sci. 170 (2000) 159-172.

36. D.R. Paul. Reformulation of the solution-diffusion theory of reverse osmosis. J. Membrane Sci. 241 (2004) 371-386.

37. S-I. Nakao and S. Kimura. Analysis of solutes rejection in ultrafiltration. J. Chem. Eng. Japan 14 (1981) 32-37.

38. E. Favre, Q.T. Nguyen, D. Sacco, A. Moncuy and R. Clement. Multicomponent polymer/solvents equilibria: an evaluation of Flory-Huggins theory for crosslinked PDMS networks swelled by binary mixtures. Chem. Eng. Comm. 140 (1996) 193-205. 
FIGURES AND TABLES

\begin{tabular}{cccc}
\hline $\begin{array}{c}\text { Sample } \\
\text { number }\end{array}$ & $\begin{array}{c}\text { Nominal dry } \\
\text { thickness of PDMS } \\
\text { layer } \mu \mathrm{m})\end{array}$ & $\begin{array}{c}\text { Irradiation dose } \\
(\mathrm{kGy} \equiv \mathrm{kJ} / \mathrm{kg})\end{array}$ & $\begin{array}{c}\text { Xylene } \\
\text { permeability } \\
\left(\times 10^{-12} \mathrm{~m}^{2} / \mathrm{s} . \mathrm{bar}\right)\end{array}$ \\
\hline & 2.0 & standard & 1.76 \\
1 & 2.0 & standard & 2.56 \\
2 & 2.0 & $50 \mathrm{kGy}$ & 2.83 \\
3 & 2.0 & $200 \mathrm{kGy}$ & 1.58 \\
4 & & &
\end{tabular}

Table 1: Properties of the membranes used in the study.

\begin{tabular}{lccccc}
\hline Material & $\begin{array}{c}\text { Density } \\
\left(\mathrm{kg} \mathrm{m}^{-3}\right)\end{array}$ & $\begin{array}{c}\text { Molecular } \\
\text { weight }\end{array}$ & $\begin{array}{c}\text { Viscosity at } \\
20^{\circ} \mathrm{C} \\
(\mathrm{mPa})\end{array}$ & $\begin{array}{c}\text { Hildebrand } \\
\text { solubility } \\
\text { parameter } \\
\left(\mathrm{MPa}^{0.5}\right)\end{array}$ & $\begin{array}{c}\text { Maximum } \\
\text { molecular } \\
\text { dimension } \\
(\mathrm{nm})\end{array}$ \\
\hline PDMS & - & - & - & 15.5 & - \\
n-heptane & 681 & 100 & 0.39 & 15.3 & 1.204 \\
cyclohexane & 779 & 84 & 0.95 & 16.8 & 0.588 \\
xylene & 861 & 106 & 0.65 & 18.2 & 0.867 \\
methanol & 791 & 32 & 0.55 & 29.2 & 0.405 \\
ethanol & 819 & 46 & 1.15 & 26.5 & 0.550 \\
n-propanol & 802 & 60 & 2.30 & 24.9 & 0.728 \\
i-propanol & 785 & 60 & 2.40 & 23.6 & 0.588 \\
MTBE & 741 & 88 & 0.27 & 18.2 & 0.495 \\
\hline
\end{tabular}

Table 2: Classification and properties of test materials. Molecular dimensions estimated using bond-lengths and covalent radii, and resolving bond angles to a particular plane.

\begin{tabular}{cccc}
\hline $\begin{array}{c}\text { Feed ethanol } \\
\text { concentration (w/w) }\end{array}$ & $\begin{array}{c}\text { Rejection } \\
\text { at 5 bar }\end{array}$ & $\begin{array}{c}\Delta \pi, \text { Van't } \\
\text { Hoff (bar) }\end{array}$ & $\begin{array}{c}\Delta \pi, \text { SD } \\
\text { (bar) }\end{array}$ \\
\hline 0.1 & 0.11 & 8.9 & \\
0.2 & 0.15 & 19.8 & 0.9 \\
0.3 & 0.14 & 22.9 & 1.7 \\
0.4 & 0.12 & 22.0 & 4.8 \\
0.5 & 0.07 & 13.4 & 5.1 \\
0.6 & 0.05 & 9.8 & 6.8 \\
0.7 & 0.03 & 5.9 & 7.9 \\
\hline
\end{tabular}

Table 3: Estimation of osmotic pressures in xylene/ethanol mixtures using Van't Hoff and solutiondiffusion approaches. 


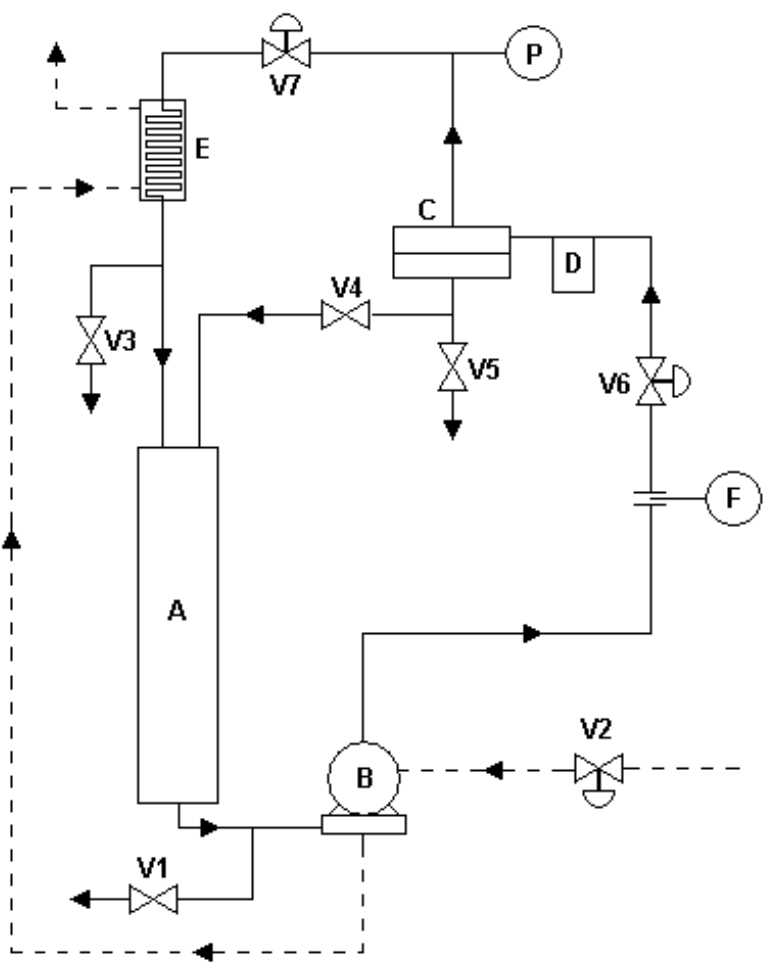

A - Reservoir

B - Air-Driven Pump

C - Membrane Module

D - Pre-Filter

E - Cooler

F - Flowmeter

$P$ - Pressure Gauge

V1 - Drain Valve

V2 - Air Regulator

V3 - Sampling Valve

V4 - Permeate Recycle Valve

V5 - Permeate Valve

V6 - Flow Control Valve

V7 - Back-Pressure Regulator

Figure 1: Schematic of the crossflow membrane filtration apparatus.

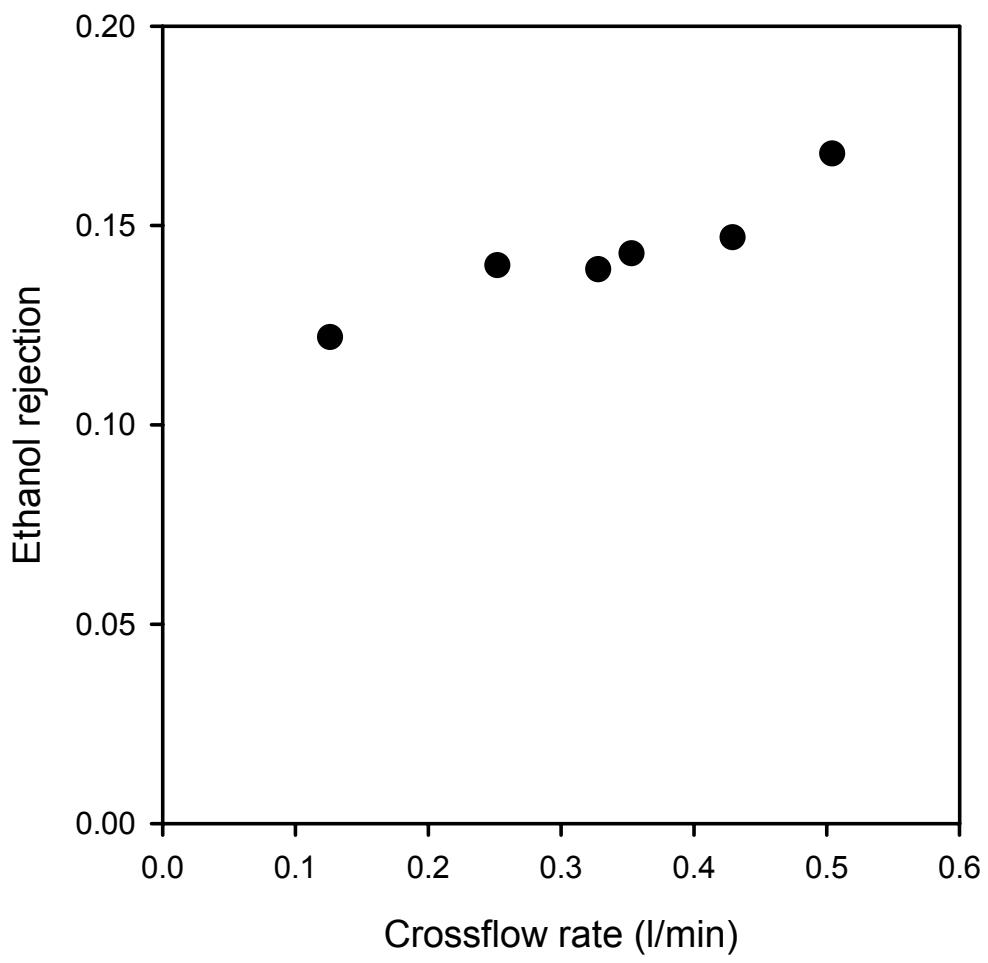

Figure 2: Effect of crossflow rate on the rejection of ethanol from a $15 \% \mathrm{w} / \mathrm{w}$ ethanol/xylene mixture using membrane sample 1. 


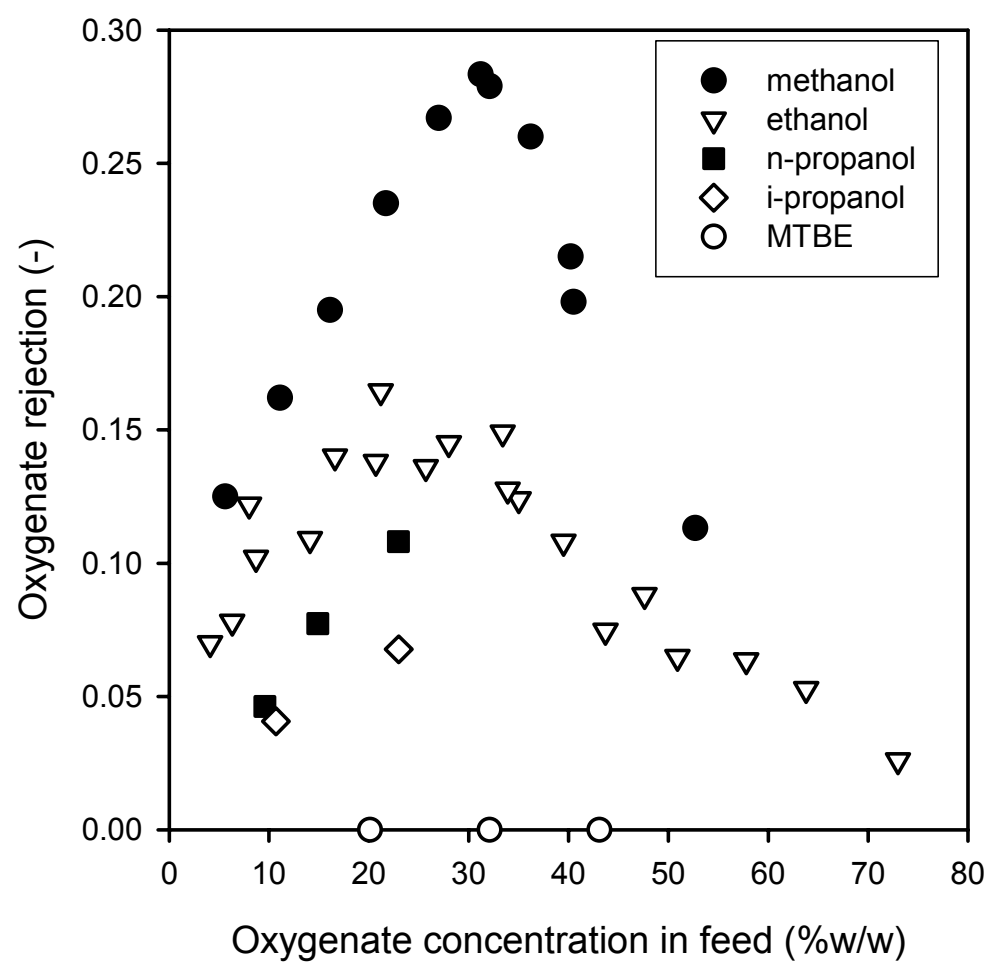

Figure 3: Effects of oxygenate type and concentration on rejection from xylene/oxygenate mixtures. Data obtained with membrane samples 1 and 2.

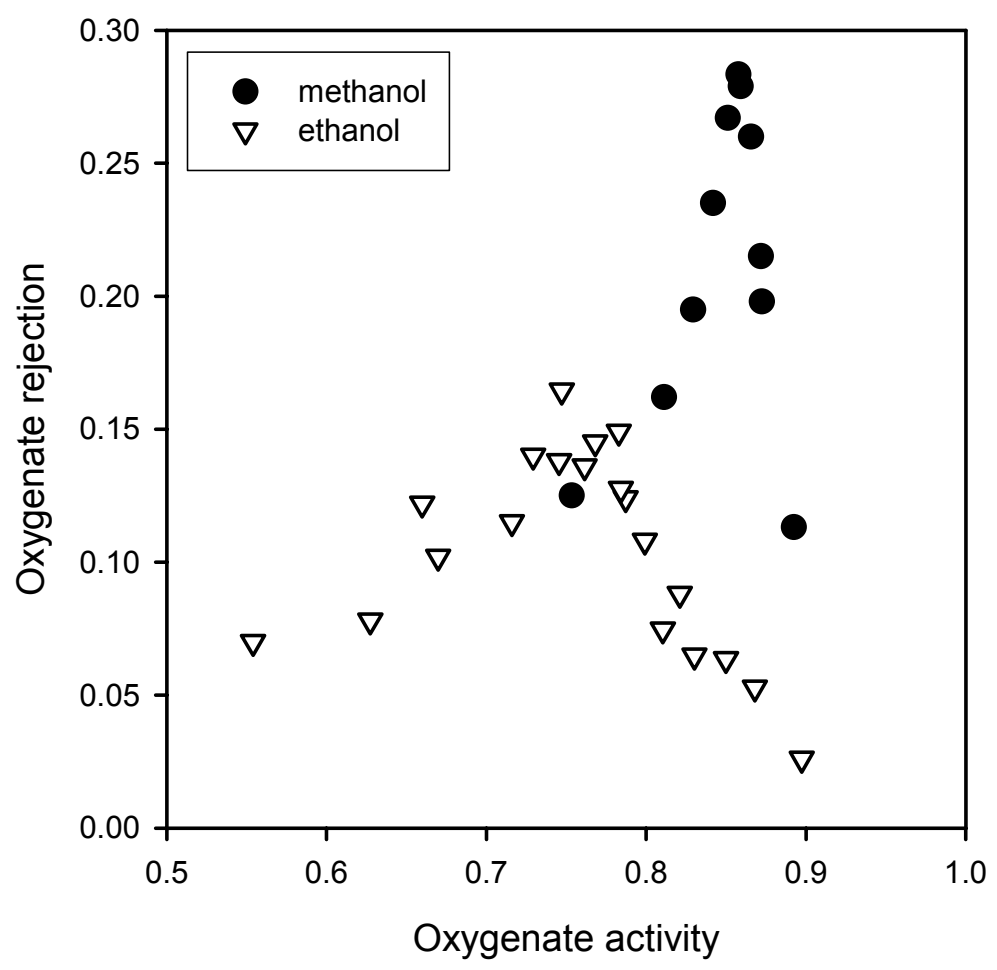

Figure 4: Effects of oxygenate type and activity on rejection. 


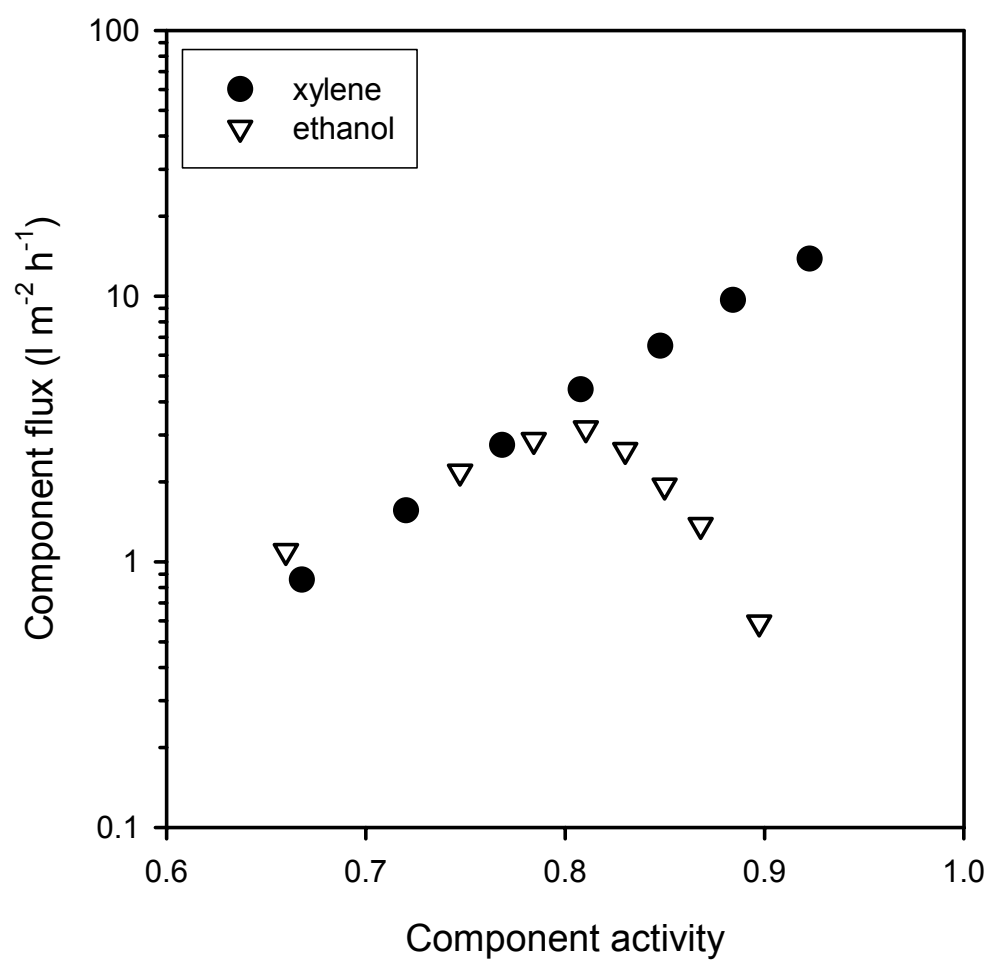

Figure 5: Ethanol and xylene fluxes at 5 bar relative to their respective activities. Data obtained using membrane sample 2.

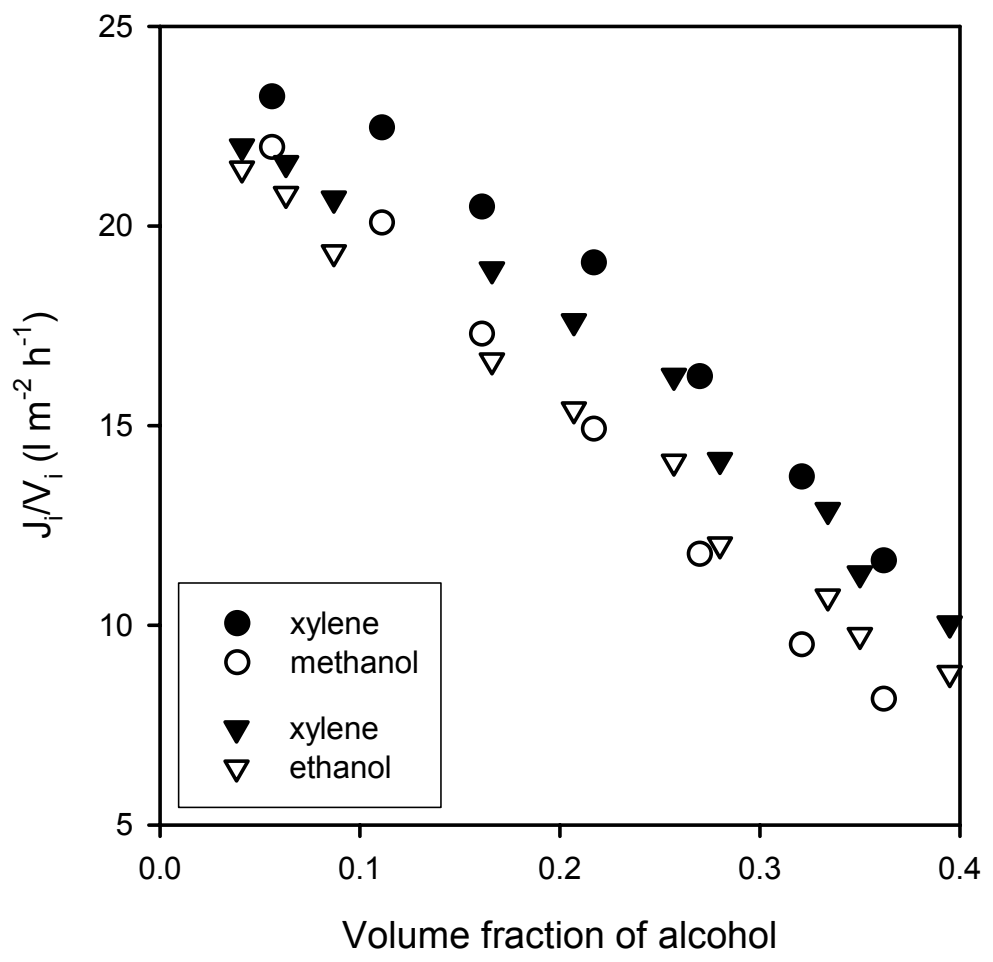

Figure 6: Concentration adjusted flux plotted against alcohol concentration for xylene/ethanol and xylene/methanol mixtures. Experiments performed at 5 bar using membrane sample 2. 


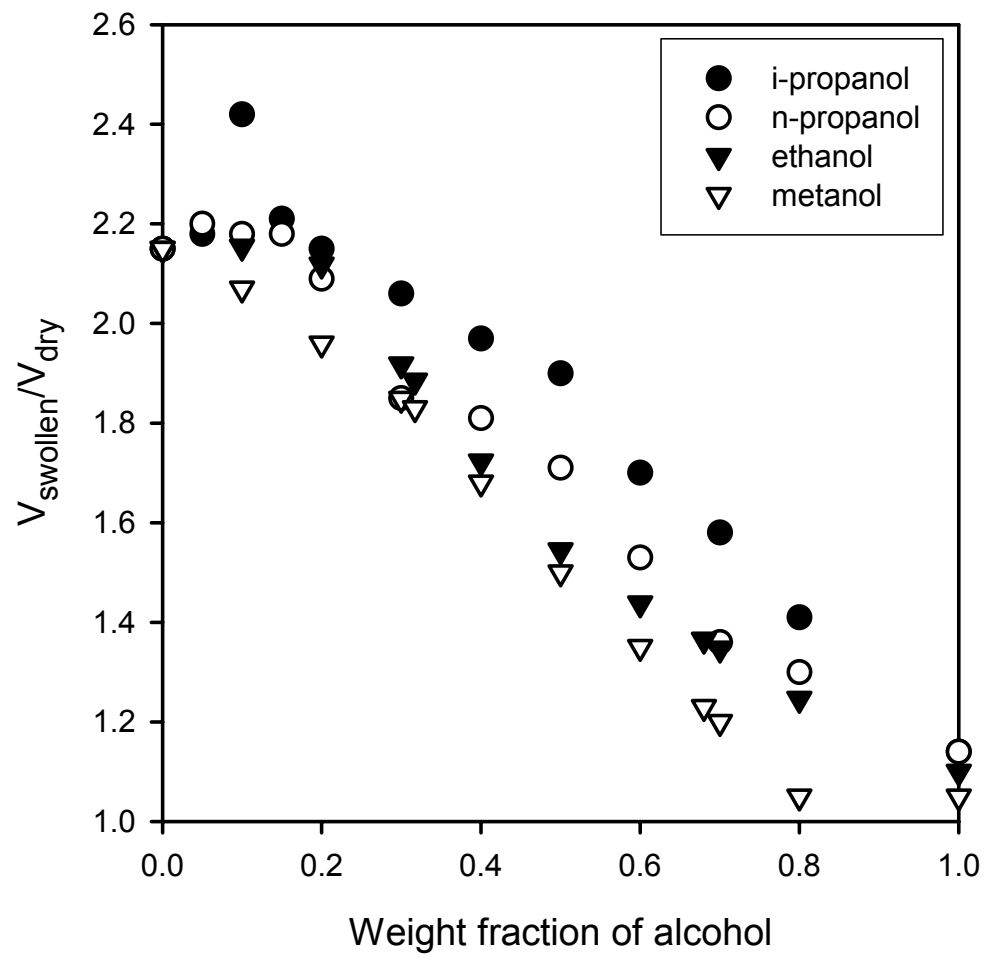

Figure 7: Degree of swelling for xylene/alcohol mixtures of varying composition, expressed as a ratio of the volume of the swollen polymer $\left(V_{\text {swollen }}\right)$ to that of the dry polymer $\left(V_{d r y}\right)$. Data taken from [33].

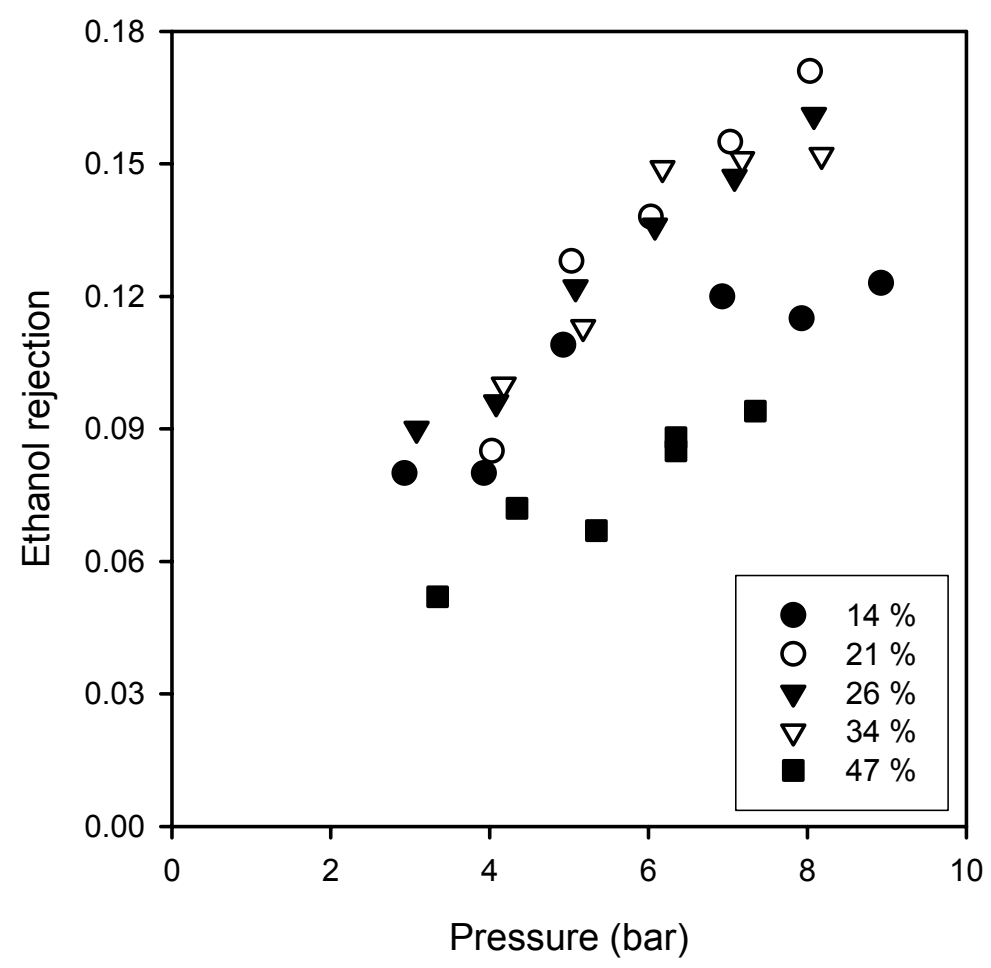

Figure 8: Effects of pressure on ethanol rejection from xylene/ethanol mixtures. Ethanol concentrations shown in legend on a weight basis. 


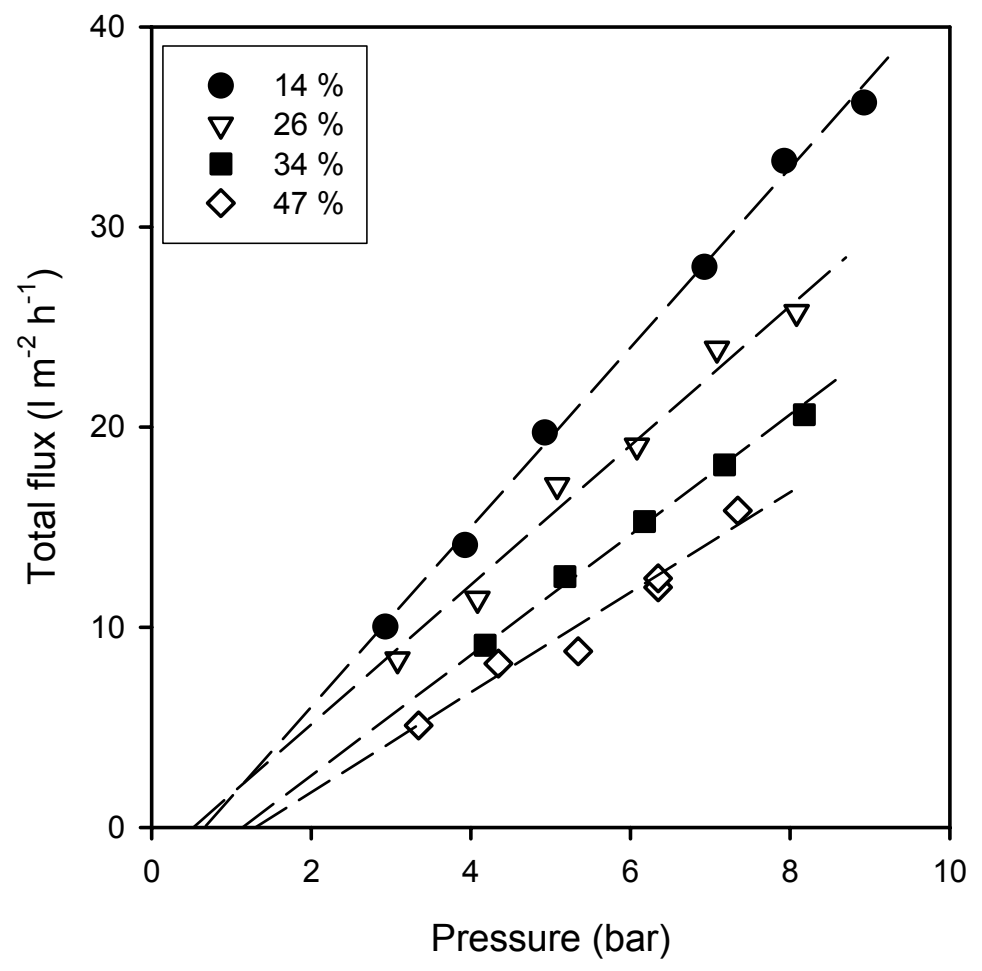

Figure 9: Effect of pressure on total flux for xylene/ethanol mixtures with non-zero intercepts highlighted by dashed lines. The ethanol concentration in each case is shown in the legend on a weight basis.

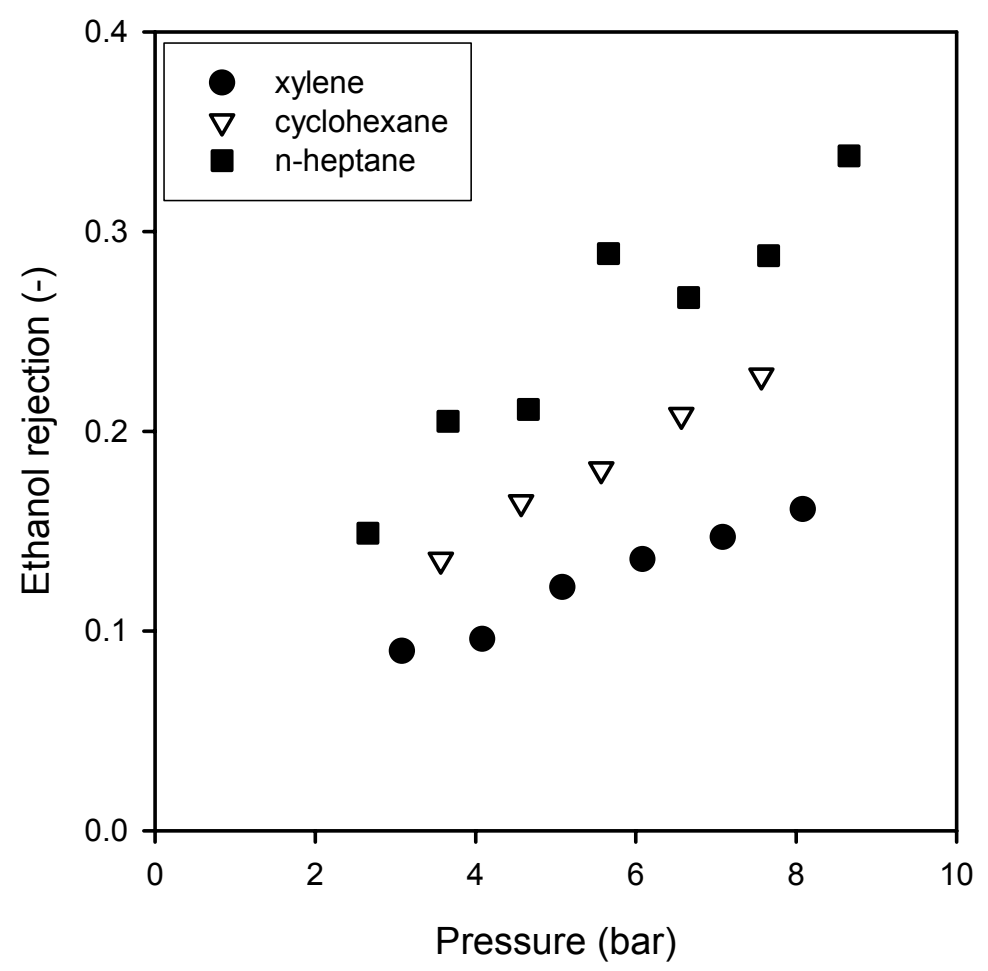

Figure 10: Effects of solvent type and pressure on ethanol rejection from a solvent/ethanol mixture; $25 \% \mathrm{w} / \mathrm{w}$ ethanol in the feed. 


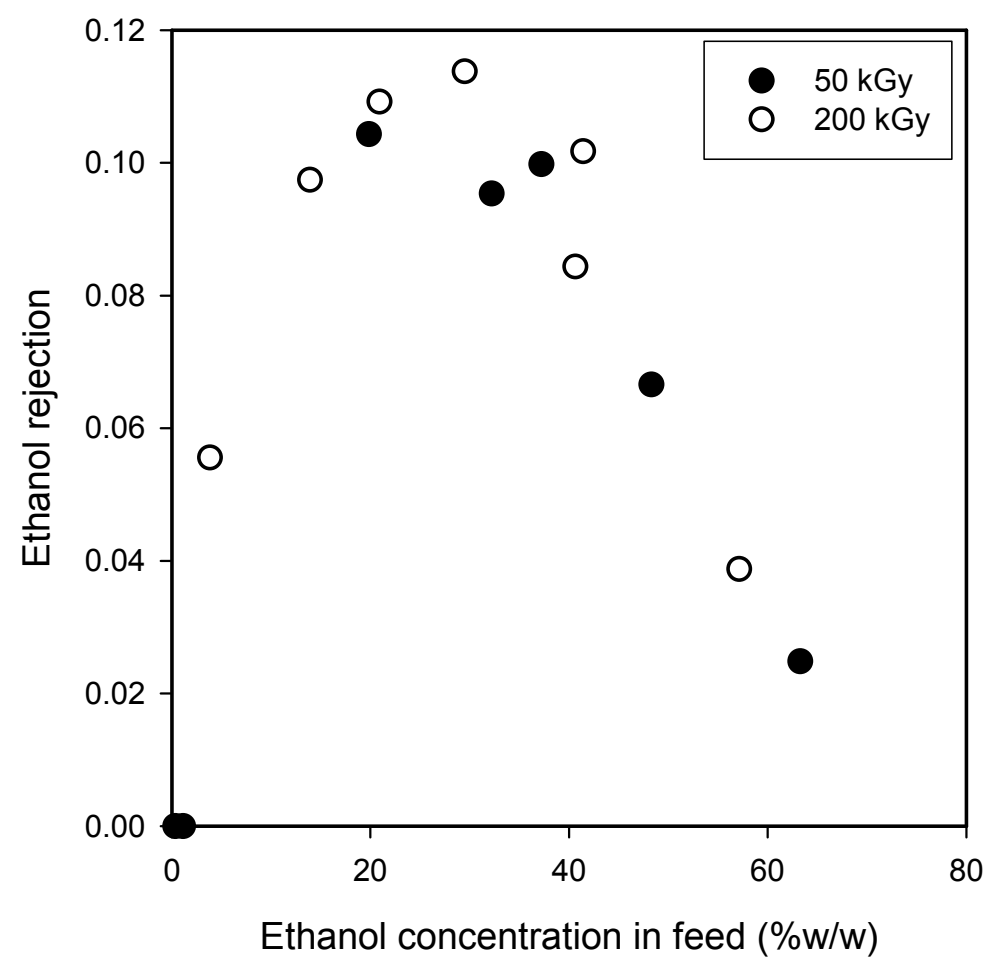

Figure 11: Ethanol rejection plotted against concentration for ethanol/xylene mixtures and membrane samples 3 (50 kGy) and 4 (200 kGy).

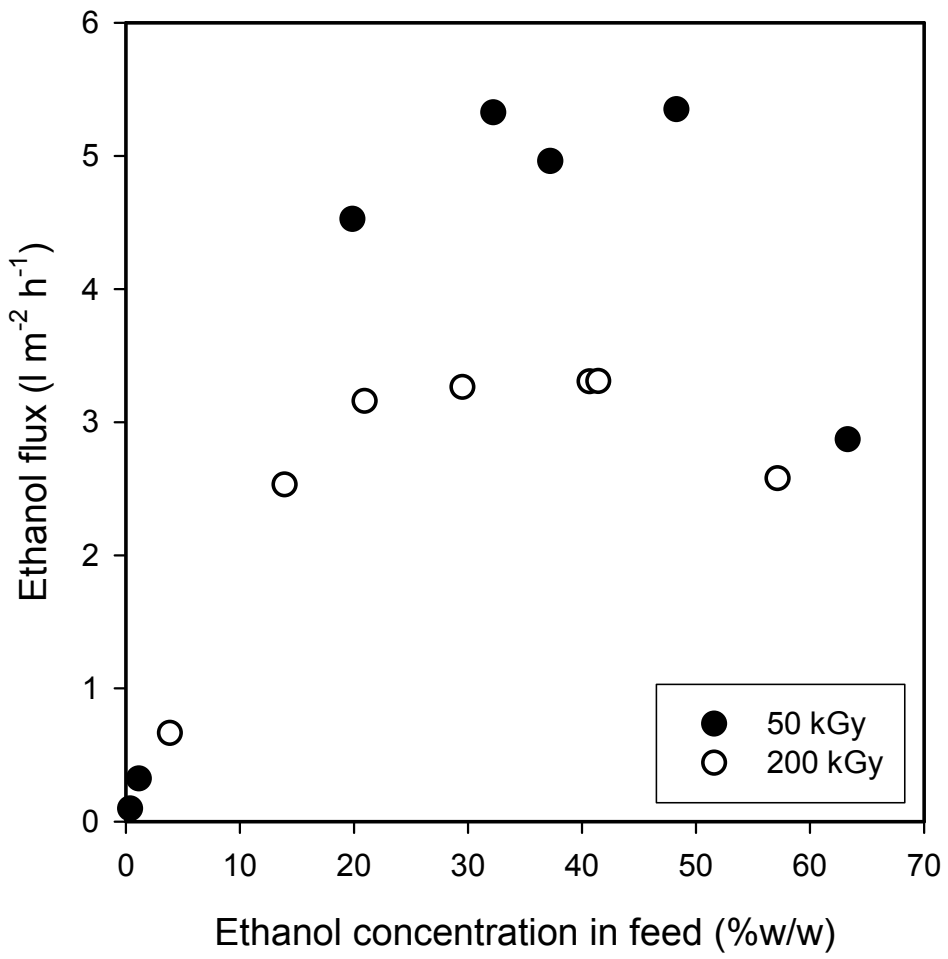

Figure 12: Ethanol flux plotted against concentration for ethanol/xylene mixtures and membrane samples 3 (50 kGy) and 4 (200 kGy). 


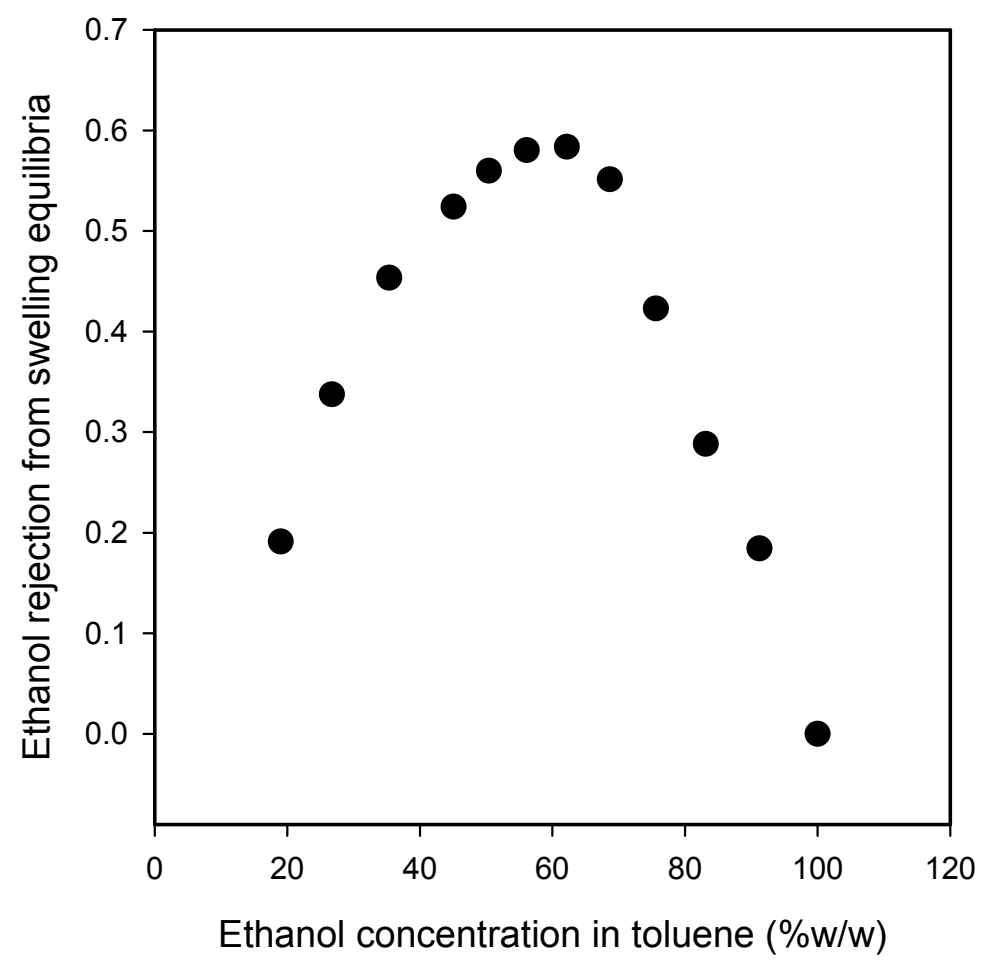

Figure 13: Ethanol rejection upon sorption into PDMS for toluene/ethanol mixtures. Data calculated from that presented by [38]. 